\title{
A Simple and Rapid Method for the Detection of Non-Ionic Surfactants
}

\author{
Minori Kamaya*, Hikaru Sugimoto, Yosuke Yamaguchi \\ Department of Environmental and Energy Chemistry, Faculty of Engineering, Kogakuin University, Hachioji, \\ Japan \\ Email: ${ }^{*}$ bt74290@ns.kogakuin.ac.jp
}

Received 17 September 2014; revised 2 November 2014; accepted 17 November 2014

Academic Editor: Morteza Bahram, Urmia University, Iran

Copyright @ 2014 by authors and Scientific Research Publishing Inc.

This work is licensed under the Creative Commons Attribution International License (CC BY).

http://creativecommons.org/licenses/by/4.0/

(c) (i) Open Access

\section{Abstract}

A spectrophotometric approach for the detection of non-ionic surfactant (Triton X-100) has been proposed in this paper. This method does not involve extraction of the ion-associate with harmful solvents, but employs adhesion of the ion-association of potassium/non-ionic surfactants complex and tetraphenylporphyrin tetrasulfonic acid obtained by vigorous shaking. The adhered ion-associate was dissolved with water and its absorbance was measured. The sensitivity for Triton X-100 was determined to be 0.146 (expressed as absorbance of $1 \mathrm{mg} / \mathrm{L}$ solution). The adhesion tendency of ion-associate was found to be dependent on the water contact angle, which in turn was influenced by a high adhesion of the ion-associate and by low blank values. In this respect, a tetrafluoroethylene vessel was found to be the most suitable for the detection of non-ionic surfactants. This spectrophotometrical method is simply and rapidly performed by a procedure based on mechanical shaking and can be employed to detect non-ionic surfactants containing more than 7 polyethylene oxide units.

\section{Keywords}

Non-Ionic Surfactant Detection, Spectrophotometry, Tetraphenylporphyrin Tetrasulfonic Acid, Ion-Associate Adhesion, Potassium/Non-Ionic Surfactant Complex

\section{Introduction}

Non-ionic surfactants are widely employed as additives in detergents for industrial and household/domestic applications. Various methods for the detection of non-ionic surfactants have been proposed [1]-[9] that are based

${ }^{*}$ Corresponding author.

How to cite this paper: Kamaya, M., Sugimoto, H. and Yamaguchi, Y. (2014) A Simple and Rapid Method for the Detection of Non-lonic Surfactants. American Journal of Analytical Chemistry, 5, 1121-1128. 
on high-performance sophisticated analytical instruments [1]-[5]; simpler and less expensive analytical tools are, however, required. Recently, a spectrophotometric approach, which is relatively inexpensive, has been proposed. This spectrophotometric method has been employed for the determination of non-ionic surfactants and is mostly based on extraction [6]-[9]. However, this method uses a series of complicated steps, and the solvents employed, such as 1,1,1-trichloroethane, chloroform, 1,2-dichlorobenzene, and benzene are often potentially harmful. To solve these issues, we propose a unique method for the determination of the ion-associate of anionic surfactants with cationic dyes on the inner wall of vessels by vigorous shaking; the ion-associate is subsequently dissolved in ethanol, and then, its absorbance is measured [10]. This idea was inspired by previous experiments that led us to the enrichment of anionic surfactants using an air bubble [11]. In this work, the enrichment procedure was carried out using the ion-associate of anionic surfactants and ethyl violet; adhesion of the ion-associate occurred in a tubular glass vessel tube and could not be achieved in solution. This led us to a determination procedure based solely on the shaking of tubes, eliminating the need for extraction. In this procedure, the ion-associate was adhered onto the wall of the glass funnel and then dissolved with ethanol, and its absorbance was measured [12]. Other methods employed adhesion of the ion-associate of anionic surfactants and crystal violet onto a polyvinyl chloride (PVA) film obtained by solution stirring [13]. The former method, however, uses smaller amounts of heptane, whereas the latter requires a tedious and complicated experimental set-up. Thus, our proposed method is more rapid and simple and is commercially available as a test kit [14]. We have thus explored the possibility of using the same principles for the determination of cationic [15] [16] and non-ionic surfactants [17].

Non-ionic surfactants do not produce ions in aqueous solutions, and are thus compatible with other types of surfactants. These are therefore excellent candidates to form complexes with potassium [18]. For instance, the non-ionic surfactant forms a complex with rubidium and potassium as well as an ion-associate with anionic dyes of tetrabromophenolphthalein ethyl ester (TBPE) [19]. This ion-association ability may be attributed to the existence of TBPE as a monovalent ion. However, TBPE, having a poor solubility in water, dissolved in methyl cellosolve, which influenced the adhesion of the ion-associate [17]. In the case of cationic surfactants, Beer's law is valid at low concentrations, when tetraphenylporphyrin tetrasulfonic acid (TPPS) without TPBE is used [16]. This result may be attributed to the fact that ion-associate formation with TPPS is stronger than that with TBPE. Thus, TPPS may be regarded as an effective counter ion for the potassium/non-ionic surfactant complex. Therefore, in this work, TPPS was used as an ion pair, instead of TBPE, for the detection of the ion-association between potassium and nonionic surfactants.

\section{Materials and Methods}

\subsection{Reagents}

All reagents were of analytical grade, and solutions were prepared with deionized water from an Organo PuricMX system. Non-ionic surfactant standard solution was prepared by dissolving $0.100 \mathrm{~g}$ of polyethylene (10) octylphenyl ether (Triton X-100, Tokyo Chemical Industry Co. Ltd.) in $1 \mathrm{~L}$ of water. A working standard solution was prepared by accurate dilution of the stock solution with water. The potassium acetate solution was prepared by dissolving $8.33 \mathrm{~g}$ of potassium acetate in $250 \mathrm{~mL}$ of water. To prepare a $2 \times 10^{-4} \mathrm{~mol} \cdot \mathrm{L}^{-1}$ solution containing the counter ion, $0.024 \mathrm{~g}$ of TPPS $\left(>98.0 \%, \mathrm{C}_{44} \mathrm{H}_{30} \mathrm{~N}_{4} \mathrm{O}_{12} \mathrm{~S}_{4} \cdot \mathrm{xH}_{2} \mathrm{O}\right.$; Tokyo Chemical Industry Co. Ltd.) was dissolved in $500 \mathrm{~mL}$ of water.

\subsection{Apparatus}

Spectrophotometric measurements were carried out with a Shimadzu UV-1800 spectrophotometer using $1 \mathrm{~cm}$ cells. Tetrafluoroethylene test vessels (FEP) $(30 \mathrm{~mL})$ were obtained from Nalgene. The vessels were used for more than one experiment. A Taitec model SR-1 horizontal shaker was used to shake the $30 \mathrm{~mL}$ FEP test tubes.

\subsection{Standard Procedure}

A sample solution $(5 \mathrm{~mL})$ that contained non-ionic surfactants was divided into 6 aliquots, which were then transferred into $30 \mathrm{~mL}$ FEP tubes. $10 \mathrm{~mL}$ of potassium acetate solution and $0.20 \mathrm{~mL}$ of TPPS solution were added into the sample. The tubes were shaken mechanically for 5 min (150 times per min). The solution was discarded, and the remaining solution was removed by tapping the tube on a paper; the ion-associate adhering to the inner vessel wall was dissolved with $5 \mathrm{~mL}$ of water. The absorbance of the solution was measured at $417 \mathrm{~nm}$ using a $1 \mathrm{~cm}$ glass cell and a spectrophotometer. 


\section{Results and Discussion}

\subsection{Effect of Using Different Types of Vessel}

The adhesion of counter dyes and ion-associate on the vessel is influenced by the type of vessel employed [12]. Thus, a selection of different vessels was investigated and their effect studied (Table 1). High blank values of 0.373 and 0.451 were obtained with TPPS used an ion pair for polycarbonate (PC) and polysulfone (PSF), respectively; in this case, vessels had hydrophilic functional groups such as carboxy and sulfonyl groups. In contrast, tetrafluoroethylene (FEP) and polypropylene (PP) are characterized by hydrophobic properties. The hydrophobicity of these polymers is typically expressed in terms of critical surface tension and water contact angle (Table 1) [17]. Our data suggested that the water contact angles depend on the adhesion of TPPS and the ion-associate on the wall. Interestingly, we found that when the contact angles were small, the blank values were large and that ion-associate adhesion was low, the opposite trend was observed when the contact angles were large. A PP vessel showed a small blank value when used for the first time; however, repeated use of this vessel caused an increase in blank values. Notably, FEP did not show this behavior and therefore, was chosen as the vessel in our experiments. The adhesion surface hydrophobicity was investigated with glass vessels via silylation with $5 \%(\mathrm{v} / \mathrm{v})$ dimethyldichlorosilane in toluene for $1 \mathrm{~d}$.

After silylation treatment of the inner surface of borosilicate, the glass tube was rinsed twice with $10 \mathrm{~mL}$ of toluene and thrice with $10 \mathrm{~mL}$ of methanol. When the silylated glass was used as a vessel, the adhesion of the ion-associate was more than that in non-treated glasses; as a result, the slope of the calibration curve for non-ionic surfactants was found to be three-fold steeper than those in non-treated glasses; the blank value was also reduced (Figure 1). This finding suggested that adhesion of the ion-associate is higher when a hydrophobic surface is used. We would like to remark that the silylated glass could not be used repeatedly because the slope of the calibration curve decreased and the blank value increased.

\subsection{Effect of Potassium Acetate Concentration}

Potassium ions form complexes with non-ionic surfactants [18], therefore, the concentration of potassium ion was investigated in our systems. Data in Figure 2 show that the absorbance reached a constant value when 7

Table 1. Effect of vessel materials.

\begin{tabular}{|c|c|c|c|c|c|}
\hline \multirow{2}{*}{ Vessel material } & \multicolumn{3}{|c|}{ Absorbance } & \multirow{2}{*}{ Critical surface tension } & \multirow{2}{*}{ Water contact angles ${ }^{* *}$} \\
\hline & Blank & Sample & Difference ${ }^{*}$ & & \\
\hline PC & 0.373 & 0.695 & 0.322 & 44 & 82 \\
\hline PSF & 0.451 & 0.693 & 0.242 & 42.1 & 70.5 \\
\hline PP & 0.140 & 0.627 & 0.487 & 30.5 & 102.1 \\
\hline FEP & 0.176 & 0.627 & 0.451 & 19.1 & 108.5 \\
\hline
\end{tabular}

${ }^{*}$ Absorbance difference between that of blank and of the sample; ${ }^{* *}$ Data were extracted from Ref. [20]; the unit of surface is $\mathrm{mJ} \cdot \mathrm{m}^{-2}$.

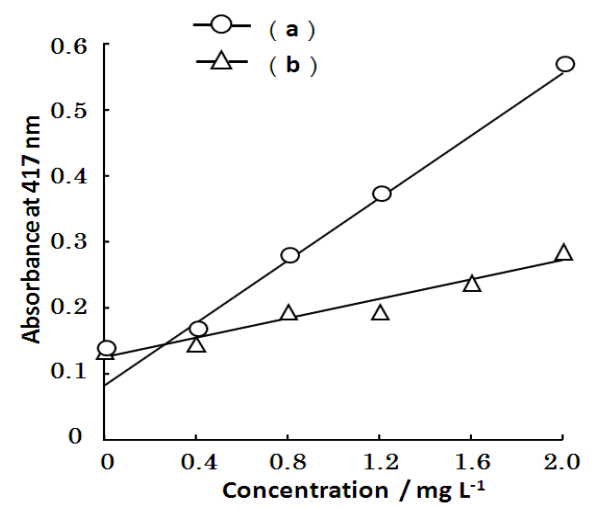

Figure 1. Effect of silylation on the adhesion to the glass vessel: (a) Silylated glass; (b) Non-silylated glass. 


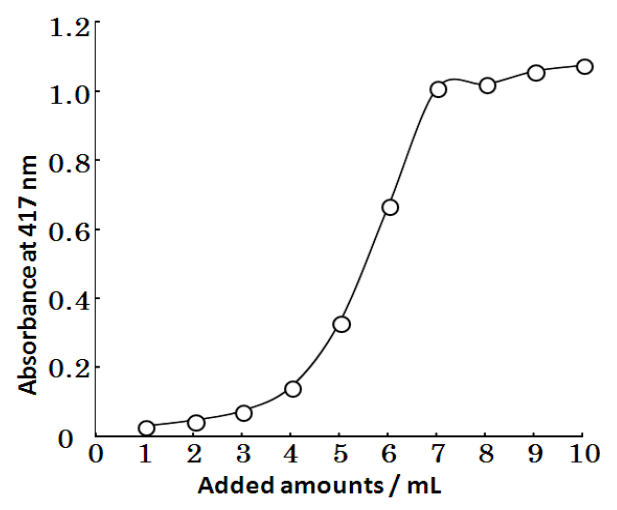

Figure 2. Effect of the addition of $4 \mathrm{~mol} / \mathrm{L}$ potassium acetate solution.

$\mathrm{mL}$ of $4 \mathrm{~mol} \cdot \mathrm{L}^{-1}$ potassium acetate solution was added. In addition, the potassium ion forms a 1:1 or 1:2 complex with the non-ionic surfactant, and 1 mole of potassium ion is surrounded with 7 oxyethylene units [20]. However, a large amount of potassium ion was necessary because potassium does not form a very strong complex with the non-ionic surfactant [21].

\subsection{Effect of Temperature}

Figure 3 shows that the absorbance of the sample and of the blank decreases when temperature is increased. In addition, we found that the difference in the absorbance between the sample and the blank is constant between $10^{\circ} \mathrm{C}$ and $30^{\circ} \mathrm{C}$. Thus, the sensitivity of our method is independent of temperature changes close to room temperature. Interestingly, when TBPE was used, the blank value hardly changed with temperature; in the case of the sample solution, we observed the maximum absorbance at temperatures around $35^{\circ} \mathrm{C}[17]$.

\subsection{Effect of $\mathrm{pH}$}

The nature of the non-ionic surfactant was not influenced by $\mathrm{pH}$ changes, because it does not contain functional groups that can be affected by $\mathrm{pH}$ changes. In contrast, the counter ions may be influenced by $\mathrm{pH}$ changes. Thus, the effect of $\mathrm{pH}$ was investigated. Data in Figure 4 show that, while the absorbance difference is virtually constant at $\mathrm{pH}$ ranges between 8 and 12, the absorbance of the sample and the blank increases at values lower than 8 . This may be due to the fact that at these $\mathrm{pH}$ values, the association of TPPS and potassium complexes of non-ionic surfactant decreases. This may also explain why the blank value hardly changed at $\mathrm{pH}$ around 8 [16].

\subsection{Effect of Shaking Time and Ratio}

Adhesion phenomena occurred when the solution was vigorously shaken. We suggest that the ion-associate gathers around the bubbles, which promote adhesion on the inner walls. Therefore, the effect of shaking time was also investigated, and the result is shown in Figure 5. Our data clearly show that absorbance reached a constant value when the shaking time was greater than 4 min.

The effect of shaking ratio (from 0 to 300 time $\cdot \mathrm{min}^{-1}$ ) was also investigated by changing the shaking speed of the shaker. Results displayed in Figure 6 show that the absorbance reached a maximum value when the shaking ratio was set to be 150 time $\cdot \mathrm{min}^{-1}$. Increasing the shaking speed further decreased the adhesion of the ion-associate.

\subsection{Effect of Sample Volume}

Bubble condition was influenced by the vacant-volume-ratio of the vessel, because bubble formation is affected by this parameter. The volume of the sample and air ratio of the inner vessel was thus investigated (Figure 7). The adhesion of the ion-associate decreased, when the vacant-volume ratio-decreased by more than $60 \%$. Thus, according to our data, the most suitable vacant-volume-ratios range between $40 \%$ and $60 \%$. 


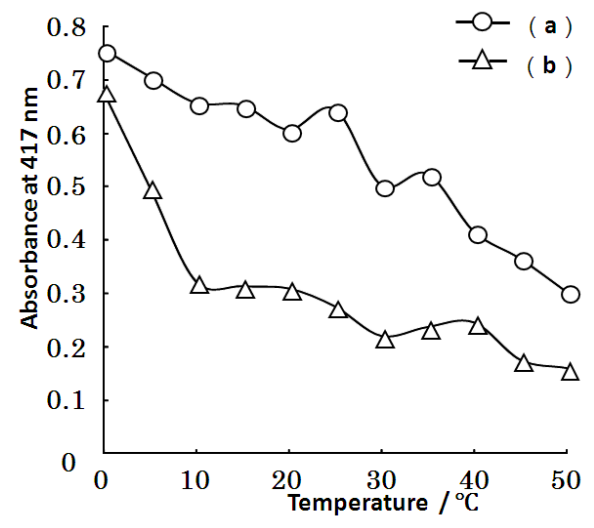

Figure 3. Effect of temperature: (a) $2 \mathrm{mg} / \mathrm{L}$ Triton X-100; (b) Blank.

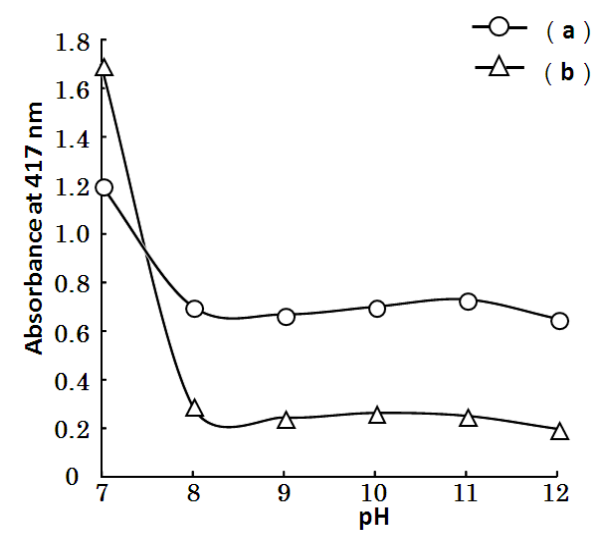

Figure 4. Effect of pH: (a) 2 mg/L Triton X-100; (b) Blank.

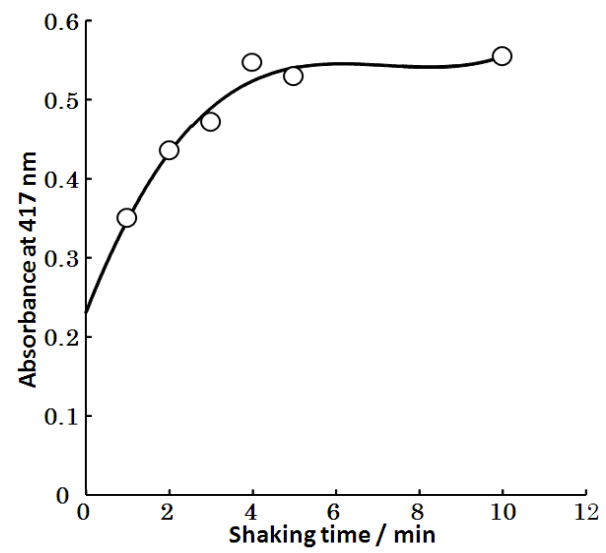

Figure 5. Effect of shaking time.

\subsection{Dissolution of Ion-Associate}

The ion-associate adhering on the inner walls was dissolved with selected solvents and spectrophotometrically monitored (Table 2). In particular, alcohol could not dissolve the ion-associate; moreover, solubility decreased when the carbon content in the alcohol increased. Notably, high dissolution was achieved only with water. In particular, when water is added, both the complex between potassium and the non-ionic surfactant and that with TPPS dissociated. The proposed method, therefore, does not require the use of solvents such as ethanol or 


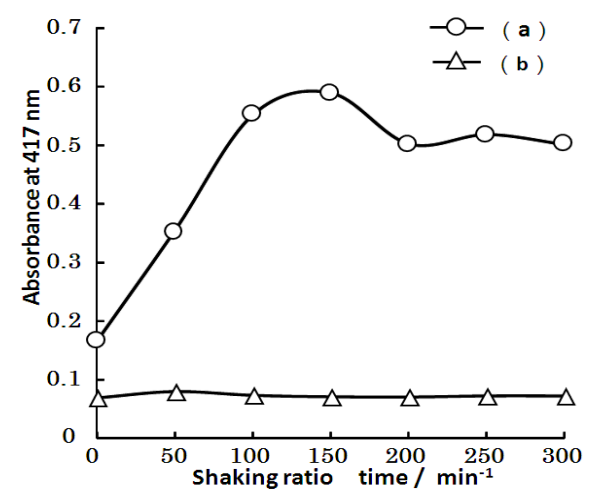

Figure 6. Effect of the shaking rate of the shaker: (a) $2 \mathrm{mg} / \mathrm{L}$ Triton X-100; (b) Blank.

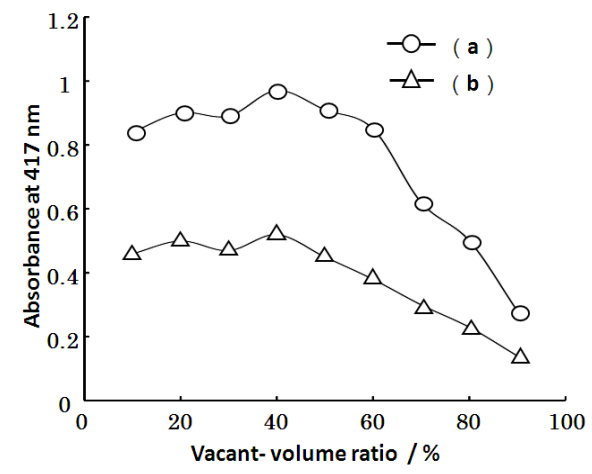

Figure 7. Effect of the vacant-volume-ratio in the vessel: (a) 2 mg/L Triton X-100; (b) Blank.

Table 2. Effect of dissolving solvent.

\begin{tabular}{|c|c|c|c|}
\hline \multirow{2}{*}{ Vessel material } & \multicolumn{3}{|c|}{ Absorbance } \\
\hline & Blank & Sample & Difference $^{*}$ \\
\hline Methycellosolve & 0.059 & 0.393 & 0.334 \\
\hline Ethylcellosove & 0.059 & 0.353 & 0.294 \\
\hline Methanol & 0.059 & 0.174 & 0.124 \\
\hline Ethanol & 0.026 & 0.031 & 0.005 \\
\hline 2-propanol & 0.015 & 0.016 & 0.001 \\
\hline Water & 0.050 & 0.468 & 0.397 \\
\hline
\end{tabular}

*Absorbance difference between that of blank and of the sample.

methyl cellosolve [10] [15]-[18].

\subsection{Calibration Curve of Triton X-100}

The calibration curve, prepared using a standard procedure, exhibits an excellent linear correlation coefficient (0.984), and the sensitivity for Triton X-100 (expressed as absorbance of $1 \mathrm{mg} \cdot \mathrm{L}^{-1}$ solution) was found to be 0.146. The molar coefficient for Triton X-100 was $1.04 \times 10^{5} \mathrm{l} \cdot \mathrm{mol}^{-1} \cdot \mathrm{cm}^{-1}$ and the detection limit is $0.2 \mu \mathrm{g} / \mathrm{L}$.

\subsection{Effect of Length of POE}

Potassium ion forms a helical coil with non-ionic surfactants; one turn of the helix consists of 6 - 7 EO units [19]. Commercially available non-ionic surfactants usually contain about ten POE units. Therefore, we investigated the effect of the number of POE units in the non-ionic surfactant, and the results are shown in Figure 8. When 


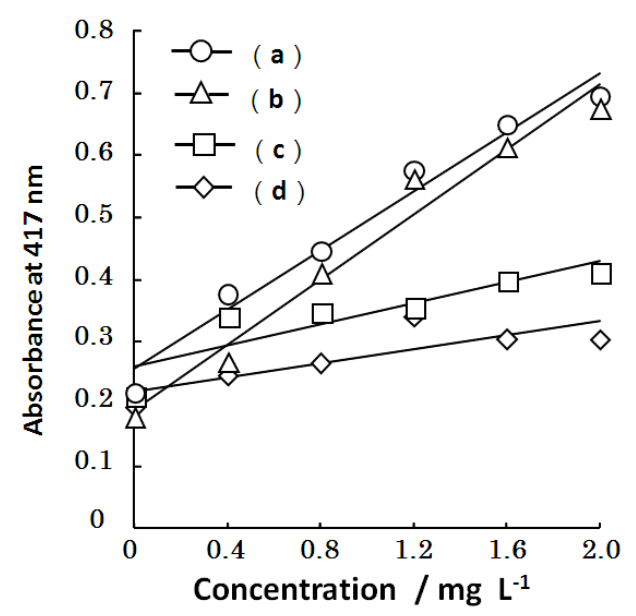

Figure 8. Calibration curves of different number of POEs in the non-ionic surfactant. The slopes of the calibration curves depend on the number (n) of polyethylene oxide units. $\left(-\mathrm{O}-\mathrm{CH}_{2} \mathrm{CH}_{2}-\mathrm{O}-\right)$ : (a) $n=7.5$; (b) $n=10$; (c) $n=5$; (d) $n=2$.

the number (n) of POE units ranged between 2 and 5, the sensitivity was low. In contrast, when $\mathrm{n}$ ranged between 7.5 and 10, the sensitivity increased. Therefore, it can be concluded that more than 7.5 units of POE are necessary to generate a complex of potassium ion with Triton X-100.

\subsection{Influence of Cationic Ions}

The influence of $1.0 \mathrm{mg} \cdot \mathrm{L}^{-1}$ of ferric, aluminium ion, and zinc ions was investigated using calibration curves for Triton X-100. A mixture of these cations showed a decrease in the slope of the calibration curve. However, addition of EDTA (as a masking agent for cations) successfully eliminated their influence. This approach was thus included in the standard procedure.

\section{Conclusion}

In this work FEP was found to be the most suitable experimental vessel; the minimum shaking time needed to obtain the highest performance was found to be 4 min. Our method can be employed to detect non-ionic surfactants containing more than 7 polyethylene oxide units. The sensitivity for Triton X-100 was determined to be 0.146 (expressed as absorbance of $1 \mathrm{mg} / \mathrm{L}$ solution). The method proposed in this work does not involve extraction of the ion-associate with harmful solvents and can be simply performed by combining a procedure based on mechanical shaking and the use of a spectrophotometer.

\section{Acknowledgements}

This work was supported by a grant-in-aid for Kogakuin University Research Institute for Science and Technology, to which the authors are very grateful.

\section{References}

[1] Marcomini, A. and Zanette, M. (1996) Chromatographic Determination on No-Ionic Aliphatic Surfactants of the Alcohol Polyethoxylate Type in the Environment. Journal of Chromatography A, 733, 193-206. http://dx.doi.org/10.1016/0021-9673(96)00009-X

[2] Boyd-Boland, A. and Pawliszyn, J. (1996) Solid-Phase Microextraction Coupled with High-Performance Liquid Chromatography for the Determination of Alkylphenol Ethoxylate Surfactants in Water. Analytical Chemistry, 68, 15211529. http://dx.doi.org/10.1021/ac950902w

[3] Ibrahim, N. and Wheals, B. (1996) Determination of Alkylphenol Ethoxylate Non-Ionic Surfactants in Trade Effluents by Sublation and High-Performance Liquid Chromatography. Analyst, 121, 239-242. http://dx.doi.org/10.1039/an9962100239 
[4] Kibbery, T., Yavaraski, T. and Hayes, K. (1996) High-Performance Liquid Chromatographic Analysis of Polydisperse Ethoxylated Non-Ionic Surfactants in Aqueous Samples. Journal of Chromatography A, 752, 155-165. http://dx.doi.org/10.1016/S0021-9673(96)00474-8

[5] di Corcia, A., Crescenzi, C., Marcomini, A. and Samperi, R. (1988) Liquid Chromatography-Electrospray-Mass Spectrometry as a Valuable Tool for Characterizing Biodegradation Intermediates of Branched Alcohol Ethoxylate Surfactants. Environmental Science \& Technology, 32, 711-718. http://dx.doi.org/10.1021/es970616x

[6] Boyd-Boland, A. and Eckert, J. (1993) Determination of Nonionic Surfactants by Spectrophotometry after Extraction with Potassium Triiodide. Analytica Chimica Acta, 271, 311-314. http://dx.doi.org/10.1016/0003-2670(93)80060-X

[7] Anderson, N. and Girling, J. (1982) Determination of Polyoxyethylene Non-Ionic Surfactants at Trace Levels. Analyst, 107, 836-838. http://dx.doi.org/10.1039/an9820700836

[8] Crisp, P., Eckert, J., Gibson, N. and Webster, I. (1981) An Extraction-Spectrophotometric Method for the Determination of Non-Ionic Surfactants. Analytica Chimica Acta, 123, 355-357. http://dx.doi.org/10.1016/S0003-2670(01)83195-0

[9] Nozawa, A. and Ohnuma, T. (1976) Re-Examination of the Microanalysis of Non-Ionic Surfactants That Contain Polyoxyethylene Chains by the Method Involving Solvent Extraction of the Thiocyanatecobaltate(II) Complex. Analyst, 101, 543-548. http://dx.doi.org/10.1039/an9760100543

[10] Kamaya, M., Tomizawa, Y. and Nagashima, K. (1998) Spectrophotometric Determination for the Determination of an Anionic Surfactant without Liquid-Liquid Extraction. Analytica Chimica Acta, 362, 157-161. http://dx.doi.org/10.1016/S0003-2670(98)00059-2

[11] Kamaya, M., Nagashima, K. and Namiki, H. (1997) Spectrophotometric Determination of Trace Amounts of Anionic Surfactant by Air Stripping-Ethyl Violet Method. Journal of Environmental Chemistry, 7, 291-295. http://dx.doi.org/10.5985/jec.7.291

[12] Sanemasa, I., Oota, A., Aoi, K. and Zheng, J.Z. (2002) Concentration on Glass Separatory Funnel Wall of Anionic Surfactants by Ion Association with Methylene Blue. Analytical Sciences, 18, 347-350. http://dx.doi.org/10.2116/analsci.18.347

[13] Naganuma, K., Hanai, T., Li, H., Sugiyama, M. and Kajiyama, M. (1996) A Simple Colorimetric Analysis for Anionic Surfactants by PVC-Film Adsorbent, the Investigation for Domestic Wastewater and Application to Environmental Education. Kagaku to Kyoiku, 44, 329-332.

http://ci.nii.ac.jp/els/110001829277.pdf?id=ART0001988112\&type=pdf\&lang=jp\&host=cinii\&order_no=\&ppv_type= 0\&lang_sw=\&no=1415077852\&cp

[14] Kamaya, M., Kaneko, Y. and Nagashima, K. (1999) Simple Method for Spectrophotometric Determination of Cationic Surfactants without Liquid-Liquid Extraction. Analytica Chimica Acta, 384, 215-218. http://dx.doi.org/10.1016/S0003-2670(98)00854-X

[15] Kamaya, M., Takahashi, J. and Nagashima, K. (2004) Rapid and Simple Determination of a Cationic Surfactant by Adsorption Induced by Vigorous Shaking. Microchimica Acta, 144, 35-39. http://dx.doi.org/10.1007/s00604-003-0109-y

[16] Kamaya, M., Hashimoto, A. and Nagashima, K. (2004) Development of a Simple Test for Ethoxylated Nonionic Surfactants. Journal of Japan Society on Water Environment, 27, 735-740. http://dx.doi.org/10.2965/jswe.27.735

[17] Sawada, K., Satoh, K., Haruta, C. and Kikuchi, Y. (1999) Partition and Complex Formation of Alkali Metal Ion with Long Chain Poly(Oxyethylene) Derivatives in 1,2-Dichloroethane. Physical Chemistry Chemical Physics, 1, 27372741.

[18] Takatori, Y., Teshima, N. and Sakai, T. (2002) Simple Determination of Nonionic Surfactants Using Ion Association Reaction. Bunseki Kagaku, 51, 849-852. http://dx.doi.org/10.2116/bunsekikagaku.51.849

[19] The Data Needed Were Extracted from the Following Page. http://www.accudynetest.com/polytable_03.html?sortby=contact_angle

[20] Yanagida, S., Takahashi, K. and Okahara, M. (1977) Metal-Ion Complexation of Noncyclic Poly(Oxyethylene) Derivatives. I. Solvent Extraction of Alkali and Alkaline Earth Metal Thiocyanates and Iodides. Bulletin of the Chemical Society of Japan, 50, 1386-1390. http://dx.doi.org/10.1246/bcsj.50.1386

[21] Sawada, K. and Kikuchi, Y. (2004) Complex Formation of Non-Cyclic Polyoxyethylenes and Their Application to Analytical Chemistry. Bunseki Kagaku, 53, 1239-1255. http://dx.doi.org/10.2116/bunsekikagaku.53.1239 
Scientific Research Publishing (SCIRP) is one of the largest Open Access journal publishers. It is currently publishing more than 200 open access, online, peer-reviewed journals covering a wide range of academic disciplines. SCIRP serves the worldwide academic communities and contributes to the progress and application of science with its publication.

Other selected journals from SCIRP are listed as below. Submit your manuscript to us via either submit@scirp.org or Online Submission Portal.
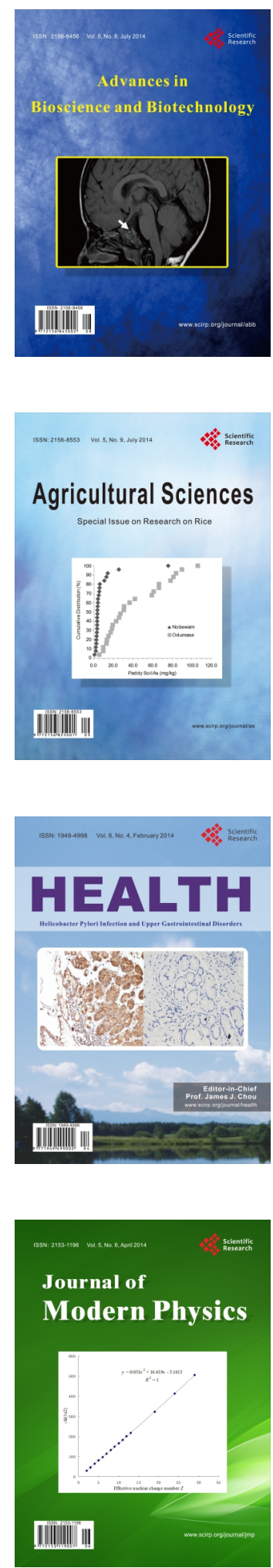
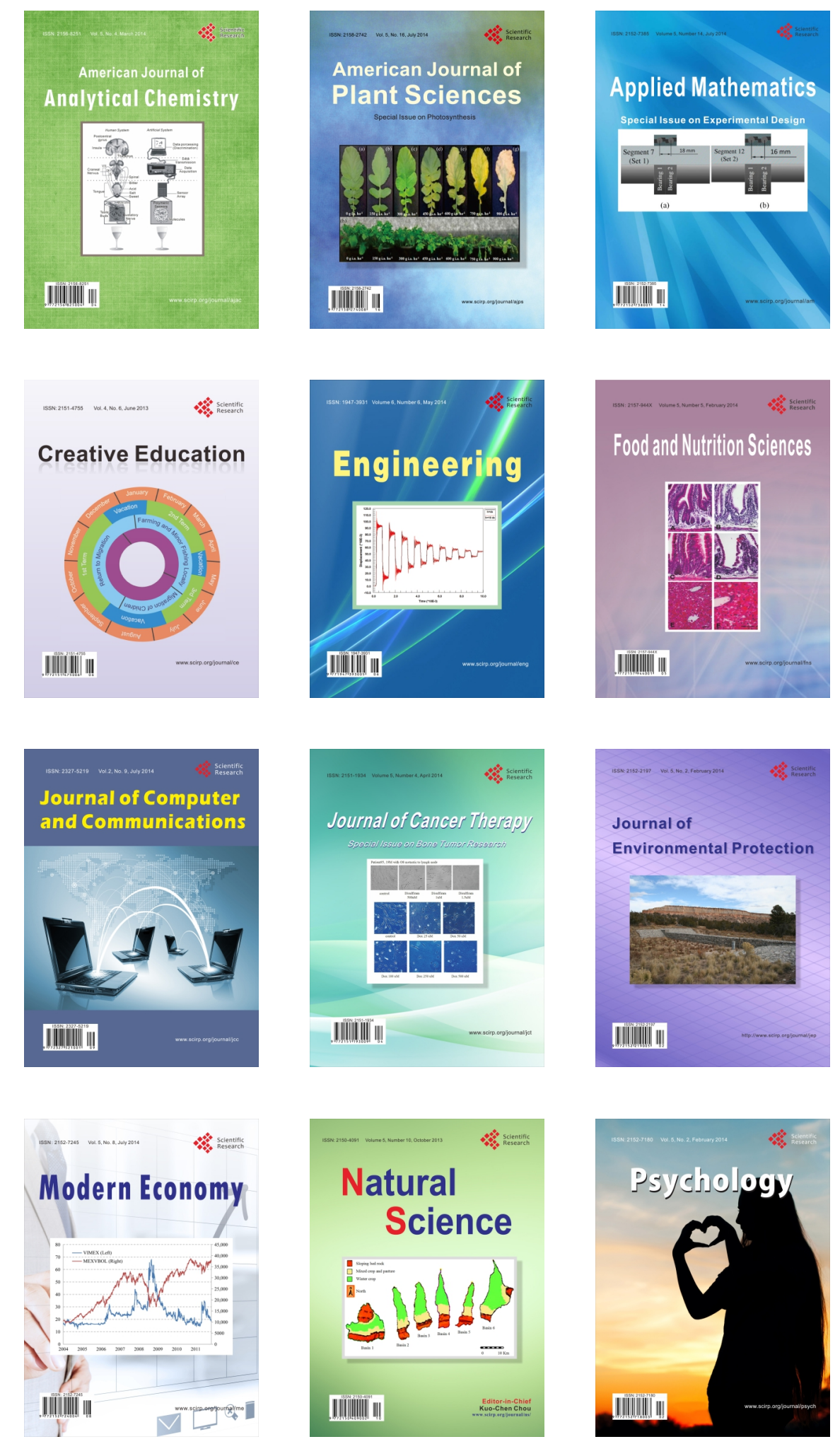